\title{
O QUANTITATIVE EASING INFLUENCIOU NO RETORNO DO MERCADO FINANCEIRO BRASILEIRO? UMA ANÁLISE POR ESTUDO DE EVENTOS E TESTES LINEARES E NÃO LINEARES
}

\author{
Herberte João França Almeida * \\ Adilson Giovanini ${ }^{\dagger}$ \\ Kleverton Clovis de Oliveira SaAth $\ddagger$
}

\begin{abstract}
Resumo
Diante da crise do Subprime, bancos centrais de diversos países utilizaram o Quantitative Easing (QE) para estimular a economia. Este trabalho utiliza dados diários, Fevereiro de 2007 a julho de 2015, de treze indicadores do mercado brasileiro e emprega a abordagem de estudo de eventos e diferentes testes lineares e não lineares para avaliar a influência do $\mathrm{QE}$ sobre os retornos desses indicadores. Os resultados encontrados indicam que, independente do teste realizado, há fortes evidências de que o QE influenciou o retorno dos ativos. Contudo, a primeira fase teve maior efeito sobre os retornos dos ativos do que as demais.
\end{abstract}

Palavras-chave: quantitative easing, estudo de eventos, retornos anormais, testes lineares e não lineares, índice bovespa.

\begin{abstract}
Facing the subprime crisis, central banks of many countries deployed Quantitative Easing (QE) to stimulate the economy. Our paper uses daily data of thirteen Brazilian market indicators from February 2007 to July 2015, employing an event study approach together with diverse linear and nonlinear tests to evaluate QE's influence in the returns of these indicators. Results suggest that, regardless of the tests performed, there are strong evidences that QE had an influence in the assets return. However, the first phase had a greater effect on the returns compared to the rest.
\end{abstract}

Keywords: quantitative easing, event study, abnormal returns, linear and nonlinear tests, bovespa index.

JEL classification: E50, E52, E58, G12.

DOI: http://dx.doi.org/10.11606/1980-5330/ea146035

\footnotetext{
* Prof. Dr. Departamento de Economia e Relações Internacionais, Universidade Federal de Santa Catarina, UFSC. Email: helberte.almeida@ufsc.br

† Prof. Dr, Departamento de Administração Pública, Universidade do Estado de Santa Catarina, UDESC. Email: adilsoneconomia@gmail.com

‡ Mestre, Programa de Pós graduação em Economia (PPGECO- UFSC). Universidade Federal de santa Catarina, UFSC. Email: klevertonsaath1995@hotmail.com
} 


\section{Introdução}

Diante da crise financeira do Subprime, que ocorreu no período 2007 - 2008, os bancos centrais dos Estados Unidos, Japão, Reino Unido e Zona do Euro recorreram à política fiscal e monetária para estimular as suas respectivas economias. No entanto, a expansão fiscal e os cortes sucessivos na taxa de juros não foram suficientes para mudar o ambiente recessivo criado pela crise financeira. Conforme a taxa de juros se aproximava de zero (zero lower bound), os bancos se viram impossibilitados de utilizar esse instrumento. Nesse contexto, bancos centrais passaram a adotar a política monetária não convencional (Quantitative Easing) para tentar estimular o crescimento econômico.

O Quantitative Easing (QE) consiste na expansão da base monetária por meio da compra de ativos financeiros públicos e privados (dívida pública, empréstimos comerciais ou ações). A política de intervenção via $\mathrm{QE}$, adotada pelo Banco Central dos Estados Unidos (FED), se divide em três fases. Precisamente, a primeira fase (QE1) teve como alvo o mercado de hipotecas, que foi o mais afetado pela crise. Nessa etapa, o FED concentrou suas ações na compra das dívidas das agências securitizadas e de ativos lastreados em hipotecas. $\mathrm{Na}$ segunda fase (QE2), o FED recorreu à compra de títulos privados para reduzir a taxa de juros de longo prazo. Por fim, na terceira fase (QE3), o FED comprou novamente os títulos de agências securitizadas no mercado imobiliário com o objetivo de garantir maior liquidez à economia norte-americana.

Embora o QE tenha por finalidade alcançar variáveis internas (liquidez, taxa de desemprego, PIB, atividade econômica), seu efeito transbordamento alcançou as economias emergentes. Entre os efeitos gerados pelos fluxos monetários internacionais oriundos dos QE cabe destacar: a saída de capital privado, apreciação nas moedas dos países emergentes, bolha no preço dos ativos e desequilíbrios financeiros.

A contribuição do presente artigo para a literatura especializada no tema consiste em verificar se os investidores realocaram seus portfólios investindo no Brasil em resposta à intervenção do FED via QE. O estudo também analisa se a intervenção do FED resultou em retornos anormais no mercado financeiro brasileiro. Para tanto, utilizam-se duas abordagens, a saber: i) estudo de eventos; ii) e a aplicação de testes que buscam identificar a presença de estruturas de dependências lineares e não lineares nas séries de retornos dos principais indicadores do mercado financeiro brasileiro. Dessa forma, o presente estudo busca realizar uma contribuição para a literatura ao considerar como objeto de análise os índices setoriais do Bovespa. Estes são de extrema importância por refletirem as expectativas econômicas desses setores.

Por fim, cabe salientar que a utilização dos indicadores setoriais possibilita a realização de uma análise individualizada para cada mercado, identificando o efeito desagregado do QE sobre a economia brasileira. Dessa forma, a metodologia utilizada possibilita a extração de um conjunto rico e elucidativo de informações a respeito dos efeitos do QE sobre o mercado financeiro nacional.

Além desta introdução, este trabalho se encontra estruturado em mais quatro seções. A seção 2 realiza uma revisão da literatura que investiga o efeito transbordamento da política de intervenção do QE nas economias em desenvolvimento. Em seguida, a seção 3 apresenta a metodologia utilizada para avaliar os impactos do QE sobre os ativos financeiros brasileiros. Posteriormente, a seção 4 mostra os resultados encontrados para o estudo de eventos e também para os testes lineares e não lineares realizados. Por fim, a seção 5 
traz algumas considerações finais.

\section{O Quantitative Easing}

\subsection{Contexto de realização do Quantitative Easing}

O termo Quantitative Easing foi criado originalmente pelo Banco Central do Japão como parte de uma política não convencional de intervenção levada a cabo entre os anos de 2001 e 2006. Segundo Fujiki et al. (2001), após a ocorrência de uma crise financeira asiática em 1997, as taxas de juros de curto prazo do Japão foram reduzidas para próximo de zero no ano de 1999. A utilização dos mecanismos convencionais de política monetária não impediram que o país ingressasse em um cenário deflacionário e recessivo. Como resultado, o Banco Central do Japão passou a adotar uma política de flexibilização quantitativa a partir de março de 2001 (Pretorius 2018). Mais precisamente, esta política possuía como objetivo aumentar a liquidez dos bancos comerciais e, desse modo, promover os empréstimos privados por meio da presença de estoques de reservas em excesso nos bancos comerciais. Ela foi realizada por meio da compra de montante de títulos do governo superior ao necessário para reduzir a taxa de juros para zero. Também foram comprados títulos, ações lastreados em ativos e papéis comerciais, o que resultou em aumento dos saldos nas contas correntes dos bancos comerciais em cerca de US\$ 300 bilhões no período entre 2001 e 2006 (Pretorius 2018).

Apesar do termo Quantitative Easing ter sido proposto apenas recentemente, sendo utilizado para denominar o conjunto de políticas monetárias não convencionais adotadas pelo Banco do Japão no período 20001-2006, cabe salientar que a primeira adoção de políticas monetárias com essas características remonta à grande depressão, que ocorreu nos Estados Unidos na década de 1930. Assim, naquele período o FED implementou políticas monetárias não convencionais de compra de ativos privados para aumentar a liquidez da economia e retirar o país do cenário de recessão em que se encontrava (Bordo 2014). Como resultado, as reservas excedentes dos bancos americanos foram superiores à $6 \%$ em 1940, enquanto desapareceram no decorrer de todo o período pós-guerra. Fato esse que evidencia a efetividade da política frente às opções convencionais no tocante ao aumento da liquidez (Homburg 2017).

Nos anos recentes, em face da crise financeira global, que emergiu após a quebra do Lehman Brothers, em setembro de 2008, e alcançou a economia de diversos países, os governos e bancos centrais dessas nações adotaram uma variedade de medidas econômicas (fiscal e monetária). Essas políticas possuíam como objetivo estabilizar as condições financeiras e sustentar a demanda agregada (Bernanke 2010).

Uma das medidas adotadas foi a utilização de política monetária convencional, ou seja, visando a recuperação no crédito e na liquidez dos seus respectivos países, os bancos centrais realizaram rodadas sucessivas de redução nas taxas de juros. Por exemplo, a taxa de juros nominal no Reino Unido que era de $5 \%$ em outubro de 2008 caiu para 0,5\% em março de 2009. Esse movimento de queda dos juros também foi registrado na economia norte-americana, que teve sua taxa de juros reduzida de $5,25 \%$ para $0,5 \%$ em menos de seis meses (Hara 2014).

Como resultado desses cortes sucessivos nas taxas de juros, elas se tornaram próximas de zero (zero lower bound), o que se mostrou insuficiente para 
fazer com que o cenário econômico interno desses países se modificasse. Conforme enfatizado por Meier (2009), os juros baixos e o ambiente recessivo que emergiu da crise financeira mostraram que os instrumentos tradicionais de política monetária não seriam suficientes para estimular a economia. Diante desse quadro, os bancos centrais passam a adotar políticas monetárias não convencionais.

Segundo Bernanke (2012), existe três maneiras de conduzir as políticas monetárias não convencionais, a saber: i) moldar as expectativas dos agentes econômicos frente à condução da política monetária; ii) mudar a composição do balanço patrimonial do Banco Central (Qualitative Easing); e iii) aumentar o tamanho do balanço patrimonial do Banco Central, isto é, a compra de ativos financeiros, expandindo a base monetária (Quantitative Easing). Durante a crise de 2008, o FED injetou cerca de US\$3,6 trilhões de dólares na economia norte-americana através da compra de ativos financeiros, quadruplicando o volume de ativos do balanço patrimonial do Banco Central. Por ter sido o mais adotado, o QE norte-americano será o foco de análise do presente estudo.

De acordo com Breedon et al. (2012), apesar do QE ser amplamente usado por diversos bancos centrais, a sua efetividade é altamente discutida. Dessa maneira, os autores salientam que para que essa política tenha sucesso é crucial que os mecanismos de transmissão da política monetária estejam funcionando, de modo que as alterações na liquidez da economia se reflitam no nível de atividade.

Uma política expansionista pode levar à formação de expectativas de inflação mais elevada no futuro. Essas expectativas se refletem na eficiência da política monetária, pois os investidores passam a exigir juros mais elevados (Hara 2014). A expectativa de inflação mais elevada também pode gerar efeito transbordamento, pois resulta na revisão das expectativas de risco dos investidores, levando-os a aplicar em ativos estrangeiros que possuem risco mais elevado, mas pagam prêmio maior.

Mediante sinalização, os anúncios do FED podem ser utilizados para informar o mercado sobre as medidas que ele pretende adotar e, possivelmente, a trajetória futura que a taxa de juros deve trilhar. De acordo com Bauer \& Rudebusch (2014), os anúncios de compra de títulos sinalizam ao mercado que as taxas de juros de longo prazo devem permanecer baixas, sendo o mesmo válido para os rendimentos. A expectativa de juros menores no futuro é outro elemento que pode gerar efeito de transbordamento, pois pode estimular os investidores a procurarem aplicações mais rentáveis em outros países.

Ademais, as intervenções do FED via QE podem modificar as taxas de juros de curto prazo, o que influencia na quantidade de títulos disponíveis, modificando toda a estrutura de taxas de juros em virtude das relações financeiras existentes entre os ativos, evidenciada pela estrutura a termo da taxa de juros. Dessa forma, como os ativos financeiros não são substitutos perfeitos no portfólio dos investidores, as mudanças nos juros levam estes a alterarem a composição da sua carteira de investimentos, os levando a buscar ativos mais rentáveis no curto prazo (Bernanke 2010).

\subsection{Evidências do Quantitative Easing}

A literatura que analisa o QE e seus diferentes impactos tem se desenvolvido e recebido importantes contribuições nos anos recentes. Diversos estudos, mediante a utilização de metodologias distintas, buscam identificar se o QE in- 
fluencia o comportamento dos ativos financeiros dos países desenvolvidos e emergentes. Na linha de estudos que analisa o impacto do QE sobre as reservas federais, destacam-se Gagnon et al. (2011). Estes mostraram que as compras do FED realizadas entre dezembro de 2008 e março de 2010 afetaram o comportamento da taxa de juro de longo prazo desse país. Seguindo linha análoga, D’Amico \& King (2010) e Hamilton \& Wu (2012) apresentam evidências que corroboram o argumento de que essas intervenções reduziram as taxas de juro de médio e longo prazo dos Estados Unidos.

Em adição, Neely et al. (2009) salientam que o QE teve repercussões importantes em taxas de juros internacionais de longo prazo e no valor à vista do dólar. Por sua vez, Krishnamurthy \& Vissing-Jorgensen (2011), Meaning \& Zhu (2011) e Joyce et al. (2011) apontam fortes evidências de que a primeira fase de intervenção do FED teve maior efeito nos juros de longo prazo do que as demais fases.

A literatura do QE também tem recebido importantes contribuições voltada para a avaliação do efeito dessa política sobre o mercado de títulos. Assim, Krishnamurthy \& Vissing-Jorgensen (2011) e Neely et al. (2009) verificam que o $\mathrm{QE}$ afetou os rendimentos do capital e as taxas de retorno dos títulos corporativos. Mais precisamente, os resultados encontrados sugerem que o QE1 exerceu impacto positivo sobre os títulos corporativos negociados nos Estados Unidos. Por sua vez, Joyce et al. (2011) avaliam os efeitos do QE realizado pelo Reino Unido. Os autores concluem que o QE reduziu os rendimentos dos títulos do governo em aproximadamente 100 pontos base no longo prazo.

Outra linha de pesquisa busca avaliar o efeito de transbordamento do QE sobre economias emergentes. Hausman \& Wongswan (2011) utilizam a metodologia de estudos de eventos para demonstrar que o QE impactou a taxa de juros corrente e futura desses países. Por sua vez, Neely (2010), utilizando a mesma metodologia, conclui que o QE realizado pelo FED gerou apreciação do dólar canadense e do yen perante o dólar americano. Por fim, Lavigne et al. (2014) analisam o efeito do QE sobre os retornos das ações de 17 países emergentes evidenciando que os anúncios do QE resultaram apenas em modificação no retorno do mercado acionário do Brasil.

Na mesma linha que essa literatura, Hara (2014), Lellis Junior (2015) e Almeida et al. (2018) avaliam os efeitos de transbordamento do QE sobre os juros, o câmbio, o preço dos ativos, o risco-país e a renda fixa do Brasil. Em suma, os resultados encontrados por esses autores mostram que o QE teve efeito nessas variáveis. Precisamente, o QE realizado pelo FED teve efeito de transbordamento e impactou a taxa de juros e no rendimento dos ativos financeiros do Brasil. Contudo, esse impacto é observado principalmente para a primeira fase de intervenção.

\section{Metodologia}

\subsection{Dados}

Para a consecução dos objetivos propostos no presente estudo, a desagregação dos retornos do mercado financeiro do Brasil se mostra de suma importância. Assim, os indicadores analisados são os índices setoriais do Bovespa, precisamente: Índice IBOVESPA; Índice Utilidade Pública (UTIL); Índice Energia Elétrica (IEE); Índice Consumo (ICON); Índice Financeiro (IFNX); Índice Industrial (INDX); Índice Materiais Básicos (IMAT); Índice de Sustentabilidade 
Empresarial (ISE); Índice Governança Corporativa - Novo Mercado (IGC-NM); Índice Governança Corporativa Trade (IGCT); Índice de Ações com Tag Along Diferenciado (ITAG); Índice Valor BM\&FBOVESPA (IVBX 2) e o Índice Dividendos BM\&FBOVESPA (IDIV).

Ademais, os dados são diários ${ }^{1}$, totalizando uma amostra com 2.100 observações referentes ao preço de fechamento desses índices para o período entre 02 de fevereiro de 2007 a 25 de julho de 2015. Cabe destacar que o elevado tamanho da amostra de dados possibilita elevada confiabilidade nos testes econométricos realizados, de modo que os resultados obtidos para os testes realizados apresentam elevado grau de robustez.

\subsection{Evento Analisado}

Conforme referido acima, o FED utilizou o QE para aumentar a liquidez da economia norte-americana. Essa intervenção pode ser dividida em três etapas distintas: QE1, QE2 e QE3. O QE1 pode ser dividido em duas intervenções, a saber: i) Em 25 de novembro de 2008, o FED anunciou a compra de mais de US\$ 500 bilhões em títulos lastreados em hipotecas (Mortgage-Backed Security - MBS) e US\$ 100 bilhões de dólares em títulos emitido por agências estatais (GSEs); ii) em 18 de março de 2009, o FED anunciou a compra de US\$300 bilhões de dólares em títulos de longo prazo, US $\$ 750$ bilhões de dólares em MBS e US\$ 100 bilhões em títulos das agências estatais.

O QE2 também pode ser discriminado em duas etapas: i) em 27 de agosto de 2010, o FED confirmou sua intenção de reinvestir o pagamento do principal proveniente de títulos comprados na rodada anterior; ii) no dia 3 de novembro de 2010, o FED comprou US\$ 600 bilhões de dólares em títulos de longo prazo do governo americano, o que elevou o montante de ativos no balanço do FED para US\$ 3 trilhões. Em 2011, o FED realiza um novo programa com o objetivo de alongar a maturidade dos ativos no seu balanço com a troca de ativos de curto prazo por ativos de longo prazo em montante equivalente à US\$ 667 bilhões até o final de 2012.

Em 13 de setembro de 2012, o FED lança uma nova rodada de intervenções, iniciando-se o QE3. Nesse dia, o FED anunciou a compra de US\$ 40 bilhões de dólares por mês dos títulos lastreados em hipotecas MBS. Posteriormente, em 12 de dezembro de 2012, o FED anunciou a compra não esterilizada (sem venda de títulos públicos) de US\$ 45 bilhões de dólares por mês em títulos de longo prazo. Como resultado, o QE3 injetou um total de US\$ 1,70 trilhões em ativos, fazendo com que o balanço do FED acumulasse um total de US\$ 4 trilhões de ativos com essa característica.

Em 19 de junho de 2013, o FED anunciou o fim do QE, com a redução gradual (Tapering) das compras de títulos, de US\$ 85 bilhões para US\$ 65 bilhões por mês a partir de setembro de 2013, sugerindo que o programa fosse encerrado em meados de 2014. Em 18 de setembro de 2013, diante da resposta negativa do mercado financeiro, o FED decidiu adiar a redução de seu programa de compra de títulos, anunciando em dezembro de 2013 que diminuiria as suas compras a partir de janeiro de 2014. As compras foram encerradas em 29 de outubro de 2014, após acumular US\$ 4,5 trilhões em ativos (Cruz 2017).

Em conjunto, esses eventos do FED resultaram em impacto na economia brasileira por meio da desvalorização da taxa de câmbio, redução na taxa de

\footnotetext{
${ }^{1}$ Os dados foram obtidos na base de dados do Economática.
} 
crescimento do PIB, aumento da inflação e deterioração da balança comercial (Lellis Junior 2015, Junior \& Galvão 2019). Ao avaliar os indicadores setorias de maneira desagregada, será possível avaliar se algum setor econômico foi mais afetado.

A Figura 1 sintetiza os eventos analisados.

Figura 1: Intervenções realizadas pelo FED

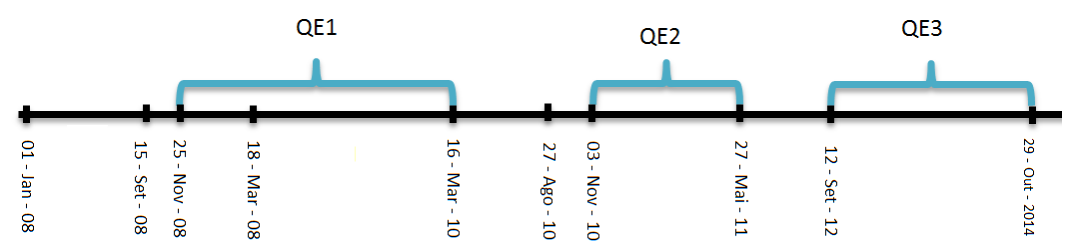

De acordo com as informações extraídas da base de dados do FED, Gráfico 2, o total de ativos no balanço do FED aumentou de US\$ 870 bilhões em agosto de 2007 para US\$2,8 trilhões em julho de 2011 e para US\$ 4,5 trilhões no início de 2015. Na sequência, refletindo o programa de redução nas intervenções, que ocorreu entre outubro de 2017 e agosto de 2019, o total de ativos diminuiu para US $\$ 3,8$ trilhões. No entanto, a partir de setembro de 2019 , o total de ativos aumenta novamente, de modo que o FED encerra o ano de 2019 com US\$ 4,13 trilhões em ativos.

Figura 2: Total de ativos no balanço do FED, em milhões US\$

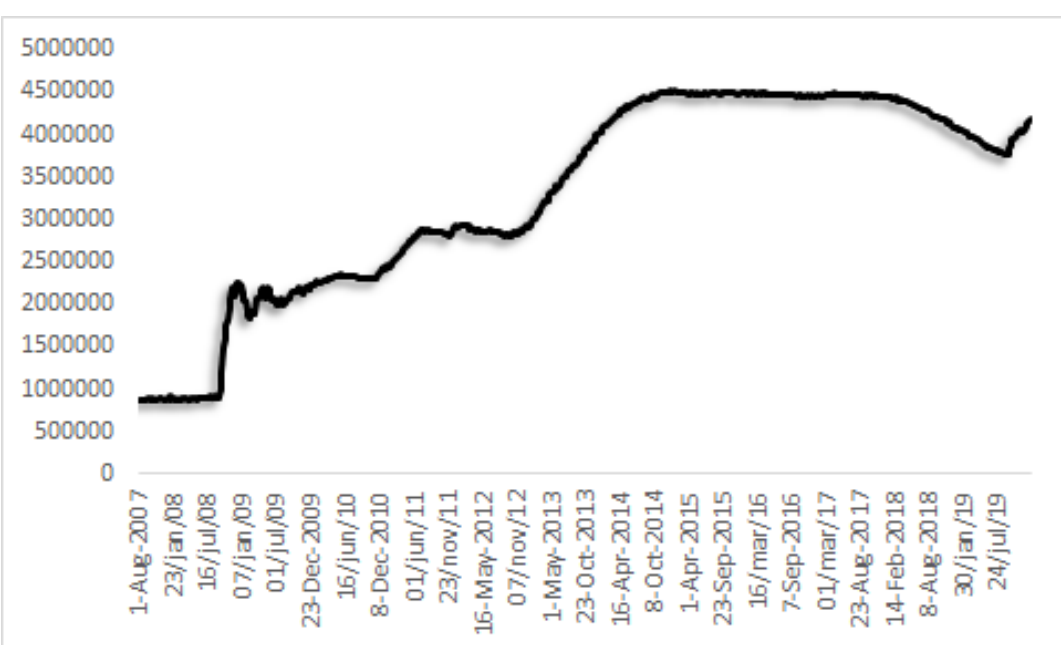

Cabe a realização de uma comparação entre a política de QE realizada pelo FED com a observada para os bancos centrais dos demais países desenvolvidos. O Banco Central do Japão, por exemplo, anunciou uma política semelhante em outubro de 2010, com a compra de US\$ 126 bilhões em ativos. Essa política foi estendida com novos anúncios em agosto e outubro de 2011, com a compra adicional de US\$ 66 bilhões em ativos. Em 4 de abril de 2013, o Banco do Japão anunciou que passaria a comprar cerca de US\$ 5 bilhões por ano, valor 
elevado para cerca de US\$ 6,50 bilhões em 31 de outubro de 2014 (Claeys \& Leandro 2016). Conforme se observa no Gráfico 3, esse país recorreu de forma contínua à compra de ativos, principalmente a partir de 2013. Como resultado, o total de ativos em posse do Banco do Japão se eleva de 1,2 trilhões de Yenes em janeiro de 2009 para 1,6 trilhões em janeiro de 2013, avançando para quase 5,8 trilhões em dezembro de 2019.

Por sua vez, o Banco Central Europeu também recorreu à intervenção através de Quantitative Easing, sendo em maio de 2009 anunciado o programa denominado Covered Bonds Purchase, com a compra de 60 bilhões de euros em obrigações hipotecárias. Já em maio de 2010 é anunciado o Securities Market Program, com a compra de 208,3 bilhões de euros em dívida soberana dos países da periferia da área do euro até o final de 2012 (Pattipeilohy et al. 2013). Em 6 de outubro de 2011 é anunciado o programa Outright Monetary Transmission, com a aquisição de 40 bilhões de euros em obrigações hipotecárias. Posteriormente, em julho de 2014, é lançado o programa Targeted Longer-Term Refinancing Operations, com o fornecimento de financiamento com prazo superior a 4 anos para instituições de crédito, sendo prorrogado em duas novas fases, anunciadas em março de 2016 e em março de 2019. Ademais, em 22 de Janeiro de 2015 é anunciado um programa mais agressivo de compra de ativos, o Expanded Asset Purchase programme (Meneses 2016). Segundo Carvalho et al. (2019), as intervenções do Banco Central Europeu no período 2015-2018 somaram US\$ 3 trilhões, de modo que a União Europeia passou a recorrer de forma recorrente ao QE para evitar que a taxa de inflação se tornasse negativa, comprometendo ainda mais o cenário econômico interno, sendo anunciada uma nova rodada de intervenções em 2019.

Figura 3: Total de ativos no balanço patrimonial do Banco Central Europeu e do Banco Central do Japão
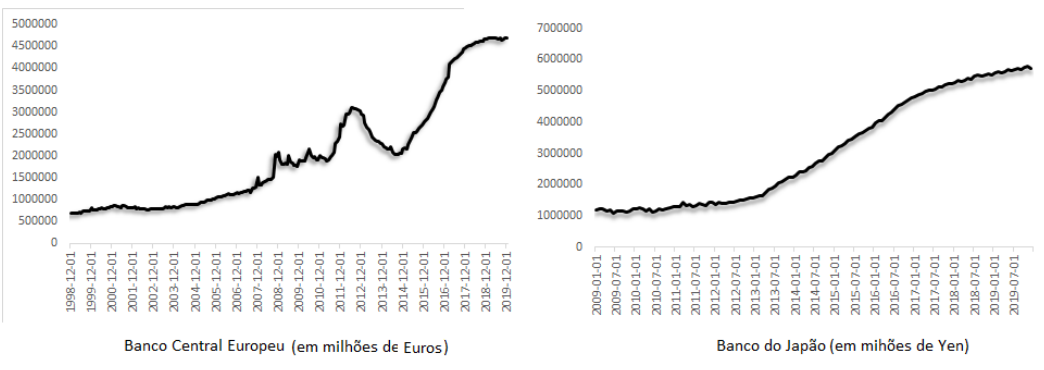
Fronte: Fred St. Louis

Com efeito, conforme se observa no Gráfico 3, no início de 2009, o Banco Central Europeu possuía o montante de 1,9 trilhões de euros em ativos da zona do euro. Volume que aumentou significativamente no início de 2011, passando para 3,1 trilhões de euros, observando-se nova rodada de compra de ativos a partir do início de 2014. Por fim, no final de 2019 ele possuía 4,6 trilhões de euros em ativos.

Entre março de 2009 e janeiro de 2010, o Banco da Inglaterra também comprou 200 bilhões de libras em ativos privados. Em outubro de 2011, diante da recessão iminente, são anunciadas compras adicionais equivalentes à 75 bilhões de libras. Posteriormente, até 2016, foram realizadas novas intervenções na ordem de 100 bilhões de libras (Freire 2017). 
Apesar dos demais países desenvolvidos também terem recorrido ao Quantitative Easing, em nenhum deles essa política alcança, no período da amostra (2007-2015), a magnitude em valores absolutos observada para o FED. Assim, o QE adotado pelos Estados Unidos é o de maior potencial de efeito sobre a cotação dos demais ativos internacionais. Todavia, conforme Neely (2019), em termos relativos, o Japão foi o país que mais recorreu aos instrumentos não convencionais de intervenção, a qual supera o montante do seu PIB em 2018. Os demais países investiram proporção consideravelmente inferior, com destaque para o Banco Central Europeu, 40\% do PIB em 2018, e FED, 25\% do seu PIB em 2014.

\subsection{Estudo de eventos}

De acordo com Fama (1970), a eficiência dos mercados significa que qualquer informação nova é transmitida imediatamente para o preço do ativo. Desse modo, a hipótese de mercados eficientes fornece os subsídios necessários para a mensuração do impacto provocado por uma nova informação. A metodologia utilizada para avaliar os efeitos do QE sobre os índices setoriais do Bovespa é a literatura denominada de "estudo de eventos". Essa metodologia já foi amplamente utilizada em trabalhos anteriores como o de Brown \& Warner (1980) e Lo \& MacKinlay (1988).

Para a elaboração de um estudo de eventos, o primeiro passo consiste na definição do evento compreendido e dos objetos de análise. O evento estudado será a política do Quantitative Easing adotada pelo banco central dos Estados Unidos e os objetos de análise são os índices setoriais do Bovespa.

Após a definição do evento e dos objetos a serem estudados, o próximo passo consiste em encontrar o retorno normal desses ativos: retorno este observado caso o evento não ocorra. Posteriormente, faz-se necessário identificar os retornos anormais no período compreendido da janela de evento específico que está sendo analisada. O objetivo de tal estudo é verificar se os retornos dos ativos no dia do evento são anormais, ou seja, diferente do retorno normal e estatisticamente significante. Caso isso ocorra, pode-se concluir que o evento possui impacto no retorno do ativo.

A janela de retornos anormais foi definida como o período de intervenção do FED, adicionada a 10 dias anteriores e 10 dias posteriores ao evento. Os respectivos períodos antes e após os eventos são adicionados para identificar se os agentes antecipam e/ou reagem à intervenção do FED. Formalmente, o retorno anormal é definido por:

$$
R A_{i t}=R_{i t}-E\left(R_{i t}\right),
$$

no qual RA denota o retorno anormal do ativo; $R$ é o retorno observado do ativo; $E(R)$ é o retorno esperado do ativo; i denota o ativo; e t o período analisado. Para avaliar o retorno esperado, considera-se que existe uma relação linear entre o retorno do mercado e o retorno do ativo. Precisamente:

$$
E\left(R_{j, t}\right)=\alpha_{t}+\beta_{j} R_{m, t},
$$

sendo $\alpha$ e $\beta$ estimados via mínimos quadrados ordinários (MQO) e correspondentes aos dados da janela de estimação anterior ao evento. Posteriormente, calcula-se o retorno anormal médio para as janelas de eventos, a saber: 


$$
A R_{t}=\frac{1}{N} \sum_{j=1}^{N} R A_{i, t} .
$$

Em posse dos retornos anormais médios acumulados, realiza-se o teste $\mathrm{t}$ para verificar se estes são estatisticamente diferentes do retorno normal. A estatística T é dada por

$$
T=\frac{A R_{t}}{S_{i t}}
$$

sendo $S$ o desvio-padrão.

\subsection{Testes lineares e não lineares}

Conforme referido acima, o objetivo do presente estudo é avaliar se o QE afetou o retorno dos índices setorias do Bovespa. Para tanto, utiliza-se da metodologia de estudo de eventos. Com a finalidade de garantir maior solidez aos resultados encontrados no estudo de eventos, utilizam-se também diversos testes sobre os retornos para identificar a presença de estruturas de dependências lineares e não lineares. Caso esses testes apontem para a presença de linearidade e/ou não linearidade nos períodos em que o estudo de eventos indica a ocorrência de retornos anormais, tem-se as evidências necessárias sobre a robustez dos resultados encontrados pelo estudo de eventos. Caso contrário, os resultados do estudo de eventos passam a ser questionados.

Como ressalta Brooks et al. (1999), os testes não lineares apresentam vantagem em relação aos testes de quebra estrutural, pois identificam as mudanças na volatilidade dos ativos e não apenas no retorno. Ademais, dado que as mudanças podem ocorrer de forma repentina e por breves períodos, essa metodologia é a mais adequada para o presente estudo. Os testes lineares e não lineares utilizados são apresentados abaixo.

\section{Testes Lineares}

\section{Teste Runs}

O teste Runs é um teste não paramétrico e tem por finalidade avaliar se uma série de observações ao longo do tempo é aleatória e independente. Para esse fim, o teste baseia-se na análise da sequência de mudanças consecutivas nos retornos. Quando a sequência é positiva, ela é uma run positiva, se a sequência é negativa, ela é uma run negativa, e, caso a sequência seja zero ela é uma run zero. A run esperada é o número de mudanças observadas no retorno se este é gerado por um processo aleatório. Se a run atual é próxima da run esperada, há evidências de que os retornos são gerados por um ruído branco. O número de runs esperadas é definido por:

$$
E R=\frac{X(X-1)-\sum_{i=1}^{3} c 2_{i}}{X}
$$

sendo $X$ o número total de runs; e $c_{i}$ o número de mudanças no retorno para cada categoria de sinal. A run esperada possui distribuição normal, para valores maiores de $X$. 


\section{Teste da Taxa de variância}

O teste da taxa de variância é capaz de distinguir aleatoriedade entre vários processos estocásticos em análise. Dada a hipótese de que o processo gerador de dados do retorno do ativo, $R_{t}$, é um ruído branco, a variância de $R_{t}+R_{t-1}$ deve ser duas vezes a variância de $R_{t}$ (Lo \& MacKinlay 1988). Formalmente:

$$
\begin{gathered}
\operatorname{VR}(2)=\frac{\operatorname{Var}\left[R_{t}(2)\right]}{2 \operatorname{Var}\left[R_{t}\right]}=\operatorname{Var}\left[R_{t}+R_{t-1}\right]= \\
\frac{\left.2 \operatorname{Var}\left[R_{t}\right]+2 \operatorname{Cov}\left[R_{t}, R_{t-1}\right]\right]}{2 \operatorname{Var}\left[R_{t}\right]}, \\
\operatorname{VR}(2)=1+\rho(1),
\end{gathered}
$$

no qual $\rho(1)$ é o coeficiente de correlação de primeira ordem dos retornos $R_{t}$. Um processo ruído branco possui autocorrelação igual a zero, o que implica que $V R(2)=1$. Esse teste pode ser estendido para qualquer número de períodos. Precisamente:

$$
V R(q)=\frac{\operatorname{Var}\left[R_{t}(q)\right]}{q \operatorname{Var}\left[R_{t}\right]}=1+2 \sum_{k=1}^{q-1}\left(1-\frac{k}{q}\right) \rho^{k},
$$

em que $R_{t}(k)=R_{t}+R_{t-1}+\cdots+R_{t-k+1}$ e $\rho(k)$ é o coeficiente de autocorrelação de ordem $k t h$, sendo $V R(q)=1 \forall q$.

A estatística do teste robusta à presença de heterocedasticidade é definida por:

$$
Z^{*}(q)=\frac{V R(q)-1}{\phi^{*}(q)^{\frac{1}{2}}},
$$

que segue distribuição normal assintoticamente. De acordo com o teste, os retornos são passeios aleatórios quando a razão de variâncias é um (1).

\section{Teste de Taxa de Variância Múltipla}

De acordo com Chow \& Denning (1993), esse teste corrige algumas limitações do teste de taxa de variância. Assim, um conjunto de taxas de variância múltiplas, para determinado número de períodos, são testadas para determinar se, conjuntamente, a taxa de variância múltipla é igual à 1 . A hipótese nula testa se o retorno do ativo é ruído branco, isto é, $M_{r}=(q i)=V R(q)-1-0$. Para um grupo de $m$ testes, esta pode ser generalizada por:

$$
\left\{M_{r}(q) \mid i=1,2, \cdots, m\right\} .
$$

As hipóteses testadas são: 


$$
\begin{aligned}
& H_{0 i}=M_{r}=0 \forall i=1,2, \cdots, m, \\
& H_{0 i}=M_{r} \neq 0 \forall i=1,2, \cdots, m,
\end{aligned}
$$

Portanto, valores estatísticos acima de 1,96 (valor absoluto), rejeitam a hipótese nula.

\subsection{Testes não lineares}

Nas últimas décadas, os estudos sobre o mercado financeiro foram dominados por ferramentas que identificam a existência de relações lineares entre o retorno dos ativos financeiros. Dessa forma, diferentes testes (autorregressivo; ruído branco; igualdade das variâncias e raiz unitária) recorrem a modelos lineares para verificar os retornos dos ativos. Todavia, Saadi et al. (2006) e Lim et al. (2006) salientam que os ativos financeiros podem não apontar correlação linear, mas podem apresentar dependência não linear. Diante desses fatos, a aplicação de testes de estacionariedade lineares é inadequada se o verdadeiro processo gerador de dados (PGD) for um processo não-linear. Portanto, o modelo linear só é válido quando os testes de não linearidade não encontram nenhuma evidência de que os ativos são afetados por não linearidades (Lim et al. 2003).

Diante do exposto acima, realizam-se alguns testes não lineares nos dados. Contudo, antes de realizar os testes para identificar a presença de estruturas de dependência não linear é preciso remover a dependência linear existente entre os retornos, sendo o modelo $\mathrm{AR}(\mathrm{p})$ utilizado com este objetivo. O número ótimo de defasagens é escolhido por meio dos critérios de informação de Akaike e Schwarz. O teste de Ljung-Box é utilizado para confirmar a eliminação da dependência linear existente entre os retornos. Posteriormente, realizam-se os testes de dependência não linear (ARCH - LM; BDS; H).

\section{Teste ARCH-LM}

O teste ARCH-LM verifica se a magnitude dos resíduos apresenta correlação com os resíduos passados. Esse teste é baseado no R2 da seguinte regressão auxiliar (Engle 1982).

$$
R_{t}^{2}=\alpha_{0}+\sum_{i=1}^{M} \alpha_{i} R_{t-i}^{2}+\epsilon_{t},
$$

que possui distribuição Qui-quadrado. Se os resíduos apresentarem estrutura ARCH, rejeita-se a hipótese nula: a volatilidade dos resíduos possui correlação serial.

\section{Teste BDS}

Desenvolvido por de Grassberger \& Procaccia (1983), esse teste é utilizado para testar se as variáveis que compõem a série são independentes e identicamente distribuídas (i.i.d). Esse teste pode detectar várias situações em que 
as variáveis não são i.i.d, tais como: estacionariedade, não linearidade e caos determinísticos.

O teste BDS usa a dimensão de correlação de Grassberger \& Procaccia (1983) para realizar um teste para uma amostra de $\mathrm{n}$ observações $x_{1}, \cdots, x_{n}$, que contenha m dimensões e possui distância $\epsilon$. A correlação integral, $C m(n, \epsilon)$, é estimada conforme segue:

$$
C_{m}(n, \epsilon)=\frac{2}{(n-m)(n-m+1)} \sum_{S=1}^{n-m} \sum_{t=S+1}^{n-m+1} I_{m}\left(x_{s}, x_{t}, \epsilon\right),
$$

em que $n$ é o tamanho da amostra, $m$ é a dimensão aninhada e $\epsilon$ é a diferença máxima entre pares de observações contadas na estimação da correlação integral. A estatística de teste é:

$$
W_{m}(\epsilon)=\sqrt{\frac{n}{\hat{V}_{m}}}\left(C_{m}(n, \epsilon)-C_{1}(m, \epsilon)^{m}\right)
$$

O teste BDS considera que a variável aleatória $\sqrt{n}\left(C_{m}(n, \epsilon)-C_{1}(n, \epsilon)^{m}\right)$ converge para uma distribuição normal assintoticamente para todo processo i.i.d. O teste BDS tem por hipótese nula a igualdade entre as séries. Portanto, valores estatísticos acima de 1,96 (valor absoluto) rejeitam a hipótese nula.

\subsection{Teste $\mathrm{H}$}

De acordo com Saadi et al. (2006) e Lim et al. (2006), para realizar o teste $H$, divide-se a série de retornos em janelas não sobrepostas, assim, se o tamanho da janela é igual a $n$, a $k$ - ésima janela é definida como:

$$
\left\{R\left(t_{k+1}\right), R\left(t_{k+1}+1\right), \cdots, R\left(t_{k+1}+n-1\right)\right\},
$$

Por sua vez, a próxima janela é definida pela seguinte sequência:

$$
\left\{R\left(t_{k}\right) R\left(t_{k}+1\right), \cdots, R\left(t_{k}+n-1\right)\right\}
$$

em que $t_{k+1}=t_{k+n}$. no qual $t k+1=t k+n$. A hipótese nula para cada janela é que o retorno é um processo estacionário com bicovariância igual a zero: um ruído branco. A hipótese alternativa é que o processo é aleatório, mas apresenta alguns períodos nos quais a bicovariância não é zero, $C_{r r r}(r, s)=$ $E[R(t) R(t+r) R(t+s)]$ com $0<r<s<L$, em que L é o numero de defasagens. Para a construção da estatística de teste, os retornos devem ser padronizados. Formalmente:

$$
Z(t)=\frac{R(t)-m_{r}}{s_{r}},
$$

em que $m_{r}$ e $s_{r}$ são a média e o desvio-padrão, respectivamente, da amostra que compõe a janela. O coeficiente de bicorrelação, Czz (r), para $r$ defasagens é definido por: 


$$
\begin{gathered}
C_{z z z}(r, s)=(n-s)^{-1} \sum_{t-1}^{n-s} Z(t) Z(t+r) Z(t+s), \\
H=\sum_{s=2}^{L} \sum_{r=1}^{s-1} G^{2}(r, s),
\end{gathered}
$$

sendo r é o número de defasagens. Por sua vez, G(r, s) é definido por:

$$
G(r, s)=(n-s)^{\frac{1}{2}} C_{z z z}(r, s),
$$

com $0<=\mathrm{r}<=$ s. O teste $\mathrm{H}$ possui distribuição Qui-quadrado com $(L-1)(L / 2)$ graus de liberdade.

\section{Resultados Encontrados}

\subsection{Resultados do Estudo de Eventos}

A Tabela 1 apresenta os resultados encontrados para o teste do estudo de eventos e todas as exposições dos resultados que se sucedem abaixo decorrem da análise dessa tabela. Dessa forma, observa-se que os agentes conseguiram prever a realização do QE dias antes de o evento ocorrer e isso impactou o Îndice Utilidade Pública (UTIL). Assim, esse índice apresentou retorno anormal negativo para dois períodos, $t-3$ e $t-2$. Portanto, o mercado brasileiro mensurado por esse índice reagiu com antecedência à ocorrência do QE e a incerteza presente no mercado internacional afetou o setor de Utilidade Pública brasileiro.

Os valores encontrados indicam que o QE também influenciou no comportamento do Índice Energia Elétrica (IEE), resultando em retorno anormal negativo. Mais precisamente, os agentes conseguiram antecipar que o FED iria realizar o QE e reagiram com dois períodos de antecedência. De modo análogo, o estudo de eventos está indicando que o QE resultou em retorno anormal positivo para o Índice Consumo (ICON) com 9 períodos de antecedência. Esses resultados sugerem que a incerteza gerada pela futura realização do QE afetou ambos os setores.

O Índice Financeiro (IFNX) apresentou retornos anormais positivos com oito dias de antecedência à realização do QE e também para seis dias após o anúncio da intervenção. Uma possível explicação para essa ocorrência é devido ao fato de que os investidores aplicaram maiores recursos em ativos desse índice ocasionando uma maior volatilidade.

Ademais, o Índice Industrial (INDX) apresentou retornos anormais positivos e negativos para os cinco períodos em análise, a saber: nove dias de antecedência ao QE (positivo); três dias de antecedência (positivo); dois dias de antecedência (negativo); oito dias após a política de intervenção (positivo); e dez dias após (positivo). Ao observar a Tabela 1, observa-se que esse índice foi o mais afetado pela política do QE. Dado que o setor industrial é consideravelmente afetado pela política monetária, esse resultado mostra que os investidores tentaram prever o preço desses ativos, considerando o impacto 
que a nova política teria sobre ele. Como a realização dessa política envolve incerteza elevada, isso acaba refletindo no valor do índice, fazendo com que os investidores revissem sucessivas vezes qual seria o impacto da política. Assim, a maior incerteza existente entre os investidores acabou contagiando o índice, provocando o aumento em sua volatilidade.

No que diz respeito ao Índice de Materiais Básicos (IMAT), verifica-se que o mesmo apresentou retorno anormal negativo para sete dias após a política de intervenção do QE e também retorno anormal positivo para 10 dias posteriores. Portanto, os resultados mostram uma desvalorização elevada dos preços dos ativos que compõe o índice, ocorrendo sua correção após dois dias.

O Índice de Sustentabilidade Empresarial (ISE) apresentou retorno anormal positivo para seis dias após a política de intervenção do FED. Por sua vez, o Índice Governança Corporativa - Novo Mercado (IGC-NM) apresentou retorno anormal positivo para nove e sete dias de antecedência a política do QE e também para seis dias após a política de intervenção. Tal resultado sinaliza que os investidores avaliaram que o QE teria um efeito positivo sobre os ativos que compõem esse índice.

O Índice de Governança Corporativa Trade (IGCT) apresentou três retornos anormais positivos para o período em análise. Assim, o índice apresentou retorno anormal positivo para nove e sete dias antes do QE e também para seis dias após. Tal resultado indica que as empresas que possuem governança corporativa diferenciada foram positivamente afetadas pelo QE.

Por sua vez, o Índice de Ações com Tag Along Diferenciado (ITAG) apresentou retorno anormal positivo para nove dias de antecedência a política monetária não convencional do QE e também para seis dias após. Esse resultado sinaliza que as empresas que oferecem melhores condições para os acionistas minoritários também foram positivamente afetadas pelo QE.

Em suma, verifica-se que a política de intervenção do QE afetou dez dos treze indicadores analisados. Além disso, a maioria dos resultados foi retornos anormais positivos e com antecedência, isto é, os agentes reagiram com antecedência à política do QE. Assim, apesar de existir elevada incerteza entre os investidores em relação a qual seria o impacto do QE sobre os ativos brasileiros, estes precificaram de forma diferenciada o impacto dessa política sobre os índices que compõem o mercado financeiro brasileiro. $\mathrm{O}$ fato de o INDX ser o índice mais afetado sinaliza que os investidores possuíam elevada incerteza sobre qual seria o impacto dessa política sobre o lado real da economia, setor industrial, utilidade pública e materiais básicos (que estavam determinando o dinamismo nacional no período). Contudo, os investidores criaram expectativas favoráveis para a grande maioria dos índices, sendo isso válido principalmente para os ativos de empresas pertencentes ao mercado financeiro e para as que possuem melhores indicadores de governança.

\subsection{Resultados dos testes lineares e não lineares}

Os testes lineares (Runs, Taxa de Variância e Taxa de Variância Múltipla) são estimados para cada índice setorial utilizando 2100 observações de retornos diários para o período entre $02 / 01 / 2007$ a 25/07/2015. A Tabela 2 apresenta os resultados encontrados para o teste Runs. Assim, verifica-se que todas as séries são estacionárias, uma vez que a run esperada (ER) é inferior ao valor encontrado na distribuição normal com nível de confiança de 95\% $(1,96)$. 
Tabela 1: Resultados encontrados pelo teste $t$ para o estudo de eventos

\begin{tabular}{|c|c|c|c|c|c|c|c|c|c|c|c|c|}
\hline Período & UTIL & IEE & ICON & IFNX & INDX & IMAT & ISE & IGC & IGCT & ITAG & IVBX2 & IDIV \\
\hline-10 & $-0,07$ & $-0,03$ & $-0,11$ & $-0,30$ & $-0,69$ & $-0,22$ & $-1,01$ & $-0,81$ & $-0,48$ & $-0,74$ & 0,07 & 0,07 \\
\hline-9 & $-0,18$ & 0,59 & $1,84^{*}$ & 0,30 & $2,31^{*}$ & 0,40 & 1,28 & $2,88^{*}$ & $2,43^{*}$ & $2,11^{*}$ & 1,36 & 0,98 \\
\hline-8 & 1,37 & 0,92 & 0,90 & $1,77^{*}$ & 0,10 & $-1,54$ & 0,70 & 0,45 & 0,73 & 1,33 & 1,10 & 1,43 \\
\hline-7 & 0,28 & 0,14 & 0,57 & 0,37 & 0,73 & 0,97 & 1,63 & $2,07^{*}$ & $1,84^{*}$ & 1,41 & 0,68 & 0,25 \\
\hline-6 & 0,66 & 0,81 & $-0,66$ & $-0,17$ & $-1,17$ & 0,51 & 0,15 & $-0,83$ & $-0,41$ & $-0,57$ & 0,64 & 0,70 \\
\hline-5 & 0,00 & 0,13 & 1,03 & $-0,89$ & 1,17 & 0,12 & $-0,33$ & $-0,63$ & $-1,46$ & $-0,60$ & 0,62 & 0,94 \\
\hline-4 & 0,74 & 0,38 & 0,04 & $-1,22$ & $-0,76$ & 0,44 & $-0,26$ & $-1,13$ & $-1,61$ & $-1,07$ & 0,47 & 1,59 \\
\hline-3 & $-1,92^{*}$ & $-1,16$ & 1,55 & $-0,77$ & $1,65^{*}$ & 0,23 & $-1,19$ & $-0,64$ & $-1,26$ & $-0,46$ & $-0,17$ & $-0,25$ \\
\hline-2 & $-3,56^{*}$ & $-2,99^{*}$ & $-0,10$ & 1,27 & $-1,76^{*}$ & $-0,39$ & 0,08 & $-0,74$ & 0,06 & $-0,37$ & $-1,15$ & $-0,93$ \\
\hline-1 & 0,30 & $-0,04$ & $-1,15$ & 0,51 & 0,84 & 1,47 & 0,85 & 0,21 & 0,09 & 0,84 & 0,61 & 0,43 \\
\hline 0 & $-0,45$ & $-0,39$ & $-0,28$ & 0,57 & 0,21 & 0,53 & 0,08 & 0,21 & 0,47 & 0,52 & $-0,23$ & 0,99 \\
\hline 1 & $-1,02$ & $-0,02$ & 1,10 & 0,30 & 1,08 & 0,01 & $-0,17$ & 1,30 & 0,98 & 0,96 & $-0,36$ & $-0,08$ \\
\hline 2 & $-0,12$ & $-0,10$ & $-0,10$ & 0,30 & $-0,14$ & 0,38 & 1,31 & 0,53 & 0,88 & 0,04 & 0,11 & 1,02 \\
\hline 3 & $-0,46$ & $-0,34$ & $-0,76$ & $-0,15$ & 0,89 & 0,94 & 1,00 & $-0,22$ & $-0,89$ & $-0,31$ & 0,28 & $-0,28$ \\
\hline 4 & 0,18 & 0,03 & $-0,15$ & 0,98 & $-0,07$ & $-0,12$ & 0,89 & $-0,58$ & $-0,47$ & 0,77 & 0,38 & 0,47 \\
\hline 5 & 0,27 & 0,41 & $-0,15$ & $-0,38$ & 1,08 & 0,15 & 0,48 & 0,57 & 0,28 & 0,31 & 0,26 & 0,00 \\
\hline 6 & 0,36 & 0,04 & 0,09 & $1,96^{*}$ & 1,08 & 0,53 & $2,18^{*}$ & $2,59^{*}$ & $2,11^{*}$ & $2,65^{*}$ & 0,56 & 1,37 \\
\hline 7 & 0,79 & 0,71 & 1,10 & $-0,53$ & $-0,22$ & $-2,09^{*}$ & 0,46 & 0,24 & $-0,92$ & $-0,02$ & 1,17 & 0,27 \\
\hline 8 & 0,19 & $-0,25$ & 0,85 & $-0,64$ & $2,23^{*}$ & 1,57 & 1,48 & 0,28 & 0,18 & $-0,23$ & 1,22 & 1,44 \\
\hline 9 & $-0,02$ & 0,40 & $-0,27$ & 0,33 & 0,84 & 0,76 & $-0,14$ & 1,14 & 0,69 & 0,91 & $-0,61$ & 0,14 \\
\hline 10 & $-0,68$ & $-0,79$ & 1,01 & $-1,28$ & $1,82^{*}$ & $2,15^{*}$ & $-0,62$ & 0,55 & 0,85 & $-0,13$ & $-0,67$ & $-0,95$ \\
\hline
\end{tabular}


Portanto, os dados apontam que os índices setoriais analisados apresentam dependência linear.

Tabela 2: Testes adicionais realizados

\begin{tabular}{l|lllllll}
\hline Teste & UTIL & IEE & IBOV & ICON & IFNX & INDX & IMAT \\
\hline Runs & $-1,26$ & $-1,37$ & 0,72 & $-0,02$ & $-0,69$ & $-0,79$ & $-0,08$ \\
\hline Teste & ISE & IGC & IGCT & ITAG & IVBX2 & IDIV & \\
\hline Runs & $-1,21$ & $-0,59$ & $-1,03$ & $-1,70$ & $-0,20$ & $-1,62$ & \\
\hline
\end{tabular}

O teste de Taxa de Variância, Tabela 3, corrobora o resultado encontrado para o teste Runs indicando que a hipótese nula de que os retornos dos ativos são um ruído branco é fortemente rejeitada para o nível de significância de $5 \%$. Dessa maneira, o resultado encontrado reforça a presença de dependência linear nos treze índices setoriais analisados.

A segunda coluna da Tabela 4 apresenta os valores encontrados para o Teste de Taxa de Variância Múltipla. Por sua vez, a terceira e quarta coluna, respectivamente, apresentam os valores encontrados para a estatística $\mathrm{z}$ e do teste do p-valor. Ao analisar os resultados, verifica-se que nenhuma das séries analisadas é um ruído branco, uma vez que o p-valor encontrado é próximo à zero para todas as séries. Assim, como salientado nos dois testes anteriores, os índices setoriais apresentam dependência linear.

A Tabela 5 apresenta o modelo selecionado pelo critério de informação de Schwarz (BIC). Conforme apresentado na metodologia, esse procedimento é necessário e tem por finalidade eliminar a dependência linear existente entre os retornos das séries estudadas. O BIC indicou que o modelo AR(1) elimina a relação em média existente entre os retornos da grande maioria das séries analisadas. Contudo, ICON, IFNX e ISE devem ser modelados com um AR(3). Além disso, UTIL e IGCT devem ser modelados através de um modelo $\operatorname{ARMA}(1,1)$.

Por sua vez, o teste de Ljung Box indica que todos os resíduos gerados pelos modelos estimados são estacionários. Esse resultado indica que os modelos $\operatorname{AR}(p)$ ou ARMA $(p, q)$ especificados conseguiram eliminar toda a dependência linear existente entre os retornos das séries financeiras. Portanto, os resíduos podem ser utilizados para testar a presença de não lineariedade nas séries.

Em posse da estimação do modelo $\operatorname{ARMA}(p, q)$, com os valores de p e q apresentados na Tabela 5, realiza-se o teste ARCH, Tabela 6. Os valores encontrados para esse teste indicam que o retorno de todas as séries analisadas é influenciado pela presença de estruturas de dependência não lineares, uma vez que o p-valor é próximo à zero.

Com relação ao teste BDS, Tabela 7, verifica-se que os p-valores são próximos a zero para os retornos de todos os ativos considerados. Esse resultado novamente indica a presença de estruturas de dependência não lineares em todos os índices setoriais analisados.

A Tabela 8 apresenta os resultados encontrados para o teste H. Esse teste foi realizado para 70 janelas, com 30 observações cada. As janelas foram escolhidas com cuidado, de modo que nenhuma das intervenções do FED via QE ficasse nas 5 observações iniciais ou nas 5 observações finais da janela. Posteriormente, a segunda e a terceira coluna da Tabela 8 , respectivamente, mostram o número e o percentual de janelas nas quais o teste $\mathrm{H}$ indicou a ocorrência 
Tabela 3: Taxa de variância

\begin{tabular}{|c|c|c|c|c|c|c|}
\hline & \multicolumn{3}{|c|}{ IBOV } & \multicolumn{3}{|c|}{ IGCT } \\
\hline Período & $\mathrm{VR}^{*}$ & Estatística $\mathrm{z}$ & $\mathrm{p}$-valor & VR & Estatística z & p-valor \\
\hline 2 & 0,4968 & $-11,54$ & 0 & 0,511 & $-10,54$ & 0 \\
\hline 4 & 0,2432 & $-9,771$ & 0 & 0,2496 & $-9,093$ & 0 \\
\hline 8 & 0,1186 & $-7,68$ & 0 & 0,1205 & $-7,229$ & 0 \\
\hline 16 & 0,0576 & $-5,653$ & 0 & 0,059 & $-5,343$ & 0 \\
\hline & \multicolumn{3}{|c|}{ ICON } & \multicolumn{3}{|c|}{ IMAT } \\
\hline Período & VR & Estatística $\mathrm{z}$ & $\mathrm{p}$-valor & VR & Estatística z & p-valor \\
\hline 2 & 0,5048 & $-10,92$ & 0 & 0,5236 & $-11,48$ & 0 \\
\hline 4 & 0,2436 & $-9,287$ & 0 & 0,2628 & $-9,942$ & 0 \\
\hline 8 & 0,1185 & $-7,317$ & 0 & 0,1237 & $-7,922$ & 0 \\
\hline 16 & 0,0587 & $-5,441$ & 0 & 0,0605 & $-5,879$ & 0 \\
\hline & \multicolumn{3}{|c|}{ IDIV } & \multicolumn{3}{|c|}{ INDX } \\
\hline Período & VR & Estatística $\mathrm{z}$ & $\mathrm{p}$-valor & VR & Estatística z & p-valor \\
\hline 2 & 0,4764 & $-10,9$ & 0 & 0,5129 & $-10,41$ & 0 \\
\hline 4 & 0,2492 & $-8,898$ & 0 & 0,2535 & $-8,87$ & 0 \\
\hline 8 & 0,1158 & $-7,134$ & 0 & 0,1205 & $-7,027$ & 0 \\
\hline 16 & 0,0572 & $-5,286$ & 0 & 0,059 & $-5,221$ & 0 \\
\hline & \multicolumn{3}{|c|}{ IEE } & \multicolumn{3}{|c|}{ ISE } \\
\hline Período & VR & Estatística $\mathrm{z}$ & $\mathrm{p}$-valor & VR & Estatística z & $\mathrm{p}$-valor \\
\hline 2 & 0,4951 & $-11,47$ & 0 & 0,5143 & $-10,24$ & 0 \\
\hline 4 & 0,2574 & $-9,482$ & 0 & 0,2494 & $-8,877$ & 0 \\
\hline 8 & 0,1193 & $-7,734$ & 0 & 0,1226 & $-7,041$ & 0 \\
\hline 16 & 0,0606 & $-5,781$ & 0 & 0,0603 & $-5,2$ & 0 \\
\hline & \multicolumn{3}{|c|}{ IFNX } & \multicolumn{3}{|c|}{ ITAG } \\
\hline Período & VR & Estatística $\mathrm{z}$ & $\mathrm{p}$-valor & VR & Estatística z & p-valor \\
\hline 2 & 0,5347 & $-10,28$ & 0 & 0,514 & $-10,37$ & 0 \\
\hline 4 & 0,2663 & $-9,321$ & 0 & 0,2548 & $-8,939$ & 0 \\
\hline 8 & 0,1286 & $-7,599$ & 0 & 0,1235 & $-7,153$ & 0 \\
\hline 16 & 0,0618 & $-5,627$ & 0 & 0,06 & $-5,284$ & 0 \\
\hline & \multicolumn{3}{|c|}{ IGC } & \multicolumn{3}{|c|}{ IVBX2 } \\
\hline Período & VR & Estatística $\mathrm{z}$ & p-valor & VR & Estatística z & p-valor \\
\hline 2 & 0,5114 & $-10,4$ & 0 & 0,4863 & $-10,72$ & 0 \\
\hline 4 & 0,2506 & $-8,942$ & 0 & 0,2477 & $-8,736$ & 0 \\
\hline 8 & 0,121 & $-7,129$ & 0 & 0,1156 & $-6,889$ & 0 \\
\hline 16 & 0,0588 & $-5,271$ & 0 & 0,0564 & $-5,063$ & 0 \\
\hline Período & \multicolumn{3}{|c|}{ UTIL } & & & \\
\hline 2 & 0,4933 & $-11,46$ & 0 & & & \\
\hline 4 & 0,2571 & $-9,471$ & 0 & & & \\
\hline 8 & 0,1211 & $-7,724$ & 0 & & & \\
\hline 16 & 0,0598 & $-5,839$ & 0 & & & \\
\hline
\end{tabular}

\footnotetext{
*VR é a Taxa de Variância.
} 
Tabela 4: Teste de Taxa de Variância Múltipla

\begin{tabular}{|c|c|c|c|c|c|c|}
\hline & \multicolumn{3}{|c|}{ IBOV } & \multicolumn{3}{|c|}{ IFNX } \\
\hline Período & $\mathrm{VR}^{*}$ & Estatística z & $\mathrm{p}$-valor & VR & Estatística z & p-valor \\
\hline 2,00 & 0,50 & $-11,54$ & 0,00 & 0,53 & $-10,28$ & 0,00 \\
\hline 4,00 & 0,24 & $-9,77$ & 0,00 & 0,27 & $-9,32$ & 0,00 \\
\hline 8,00 & 0,12 & $-7,68$ & 0,00 & 0,13 & $-7,60$ & 0,00 \\
\hline 16,00 & 0,06 & $-5,65$ & 0,00 & 0,06 & $-5,63$ & 0,00 \\
\hline & \multicolumn{3}{|c|}{ ICON } & \multicolumn{3}{|c|}{ IGC } \\
\hline Período & VR & Estatística z & p-valor & VR & Estatística z & $p$-valor \\
\hline 2,00 & 0,50 & $-10,92$ & 0,00 & 0,51 & $-10,40$ & 0,00 \\
\hline 4,00 & 0,24 & $-9,29$ & 0,00 & 0,25 & $-8,94$ & 0,00 \\
\hline 8,00 & 0,12 & $-7,32$ & 0,00 & 0,12 & $-7,13$ & 0,00 \\
\hline 16,00 & 0,06 & $-5,44$ & 0,00 & 0,06 & $-5,27$ & 0,00 \\
\hline & \multicolumn{3}{|c|}{ IDIV } & \multicolumn{3}{|c|}{ IGCT } \\
\hline Período & VR & Estatística z & $\mathrm{p}$-valor & VR & Estatística z & p-valor \\
\hline 2,00 & 0,48 & $\begin{array}{l}-10,90 \\
\end{array}$ & 0,00 & 0,51 & $\begin{array}{l}-10,54 \\
\end{array}$ & 0,00 \\
\hline 4,00 & 0,25 & $-8,90$ & 0,00 & 0,25 & $-9,09$ & 0,00 \\
\hline 8,00 & 0,12 & $-7,13$ & 0,00 & 0,12 & $-7,23$ & 0,00 \\
\hline 16,00 & 0,06 & $-5,29$ & 0,00 & 0,06 & $-5,34$ & 0,00 \\
\hline & \multicolumn{3}{|c|}{ IEE } & \multicolumn{3}{|c|}{ IMAT } \\
\hline Período & VR & Estatística z & $\mathrm{p}$-valor & VR & Estatística $\mathrm{z}$ & $\mathrm{p}$-valor \\
\hline 2,00 & 0,50 & $-11,47$ & 0,00 & 0,52 & $-11,48$ & 0,00 \\
\hline 4,00 & 0,26 & $-9,48$ & 0,00 & 0,26 & $-9,94$ & 0,00 \\
\hline 8,00 & 0,12 & $-7,73$ & 0,00 & 0,12 & $-7,92$ & 0,00 \\
\hline 16,00 & 0,06 & $-5,78$ & 0,00 & 0,06 & $-5,88$ & 0,00 \\
\hline & \multicolumn{3}{|c|}{ ISE } & \multicolumn{3}{|c|}{ INDX } \\
\hline Período & VR & Estatística z & $\mathrm{p}$-valor & VR & Estatística z & $\mathrm{p}$-valor \\
\hline 2,00 & 0,51 & $-10,24$ & 0,00 & 0,51 & $-10,41$ & 0,00 \\
\hline 4,00 & 0,25 & $-8,88$ & 0,00 & 0,25 & $-8,87$ & 0,00 \\
\hline 8,00 & 0,12 & $-7,04$ & 0,00 & 0,12 & $-7,03$ & 0,00 \\
\hline 16,00 & 0,06 & $-5,20$ & 0,00 & 0,06 & $-5,22$ & 0,00 \\
\hline
\end{tabular}

*VR é a Taxa de Variância Múltipla.

Tabela 5: Modelo $\operatorname{ARMA}(p, q)$ selecionado

\begin{tabular}{l|cccl}
\hline Indicador & $p$ & $q$ & BIC & Lujung Box \\
\hline UTIL & 1 & 1 & $2,849,268$ & 0,60 \\
IEE & 1 & 0 & $2,848,679$ & 0,91 \\
IBOV & 1 & 0 & $2,849,136$ & 0,67 \\
ICON & 3 & 0 & $2,850,135$ & 0,56 \\
IFNX & 3 & 0 & $2,847,501$ & 0,94 \\
INDX & 1 & 0 & $2,851,748$ & 0,62 \\
IMAT & 1 & 0 & $2,845,970$ & 0,46 \\
ISE & 3 & 0 & $2,847,345$ & 0,92 \\
IGC & 1 & 0 & $2,850,965$ & 0,95 \\
IGCT & 1 & 1 & $2,845,173$ & 0,52 \\
ITAG & 1 & 0 & $2,845,273$ & 0,53 \\
IVBX2 & 1 & 0 & $2,844,239$ & 0,36 \\
IDIV & 1 & 0 & $2,847,763$ & 0,51 \\
\hline
\end{tabular}


Tabela 6: Testes ARCH-LM

\begin{tabular}{l|lllllll}
\hline Teste & UTIL & IEE & IBOV & ICON & IFNX & INDX & IMAT \\
\hline ARCH-LM & 76,13 & 61,08 & 74,51 & 63,25 & 84,55 & 88,44 & 44,83 \\
\hline Teste & ISE & IGC & IGCT & ITAG & IVBX2 & IDIV & \\
\hline ARCH-LM & 142,44 & 89,90 & 106,16 & 99,58 & 87,92 & 48,11 & \\
\hline
\end{tabular}

de não lineariedades. Os índices IMAT, IGCT e o IVBX2 são os ativos para os quais menos se observa a ocorrência de não lineariedades, apenas em 3 janelas cada. Por outro lado, o IEE, o IFNX, o INDX e o ISE são os índices que mais foram influenciados pela ocorrência de eventos não lineares, 6 vezes cada.

A quarta coluna da Tabela 8 identifica as janelas em que o FED atua no mercado via $\mathrm{QE}$ e o teste $\mathrm{H}$ indica a ocorrência de não lineariedade. De acordo com o teste H, o UTIL é o índice mais influenciado pelo QE, sendo encontrada formação de estruturas de dependência não lineares nas duas intervenções do FED via QE1 e na primeira intervenção via QE3. Por sua vez, o IEE é o segundo indicador financeiro mais influenciado pelas intervenções não convencionais realizadas pelo FED, as duas intervenções do FED via QE1 levam à formação de estruturas de dependência não lineares nesse índice. Em suma, pode-se afirmar que o teste $\mathrm{H}$ realizado neste estudo encontra resultado semelhante aos encontrados por Hara (2014), Lellis Junior (2015) e Almeida et al. (2018), isto é, os indicadores analisados são afetados pela primeira etapa do QE1, mas não são afetados pelas demais intervenções. A principal explicação para esse acontecimento é que o primeiro anúncio do QE realizado pelo FED em 25 de agosto de 2008 gerou incerteza no mercado financeiro. Como essa política nunca tinha sido realizada os agentes tinham muitas dúvidas em relação ao modo como o FED iria operacionalizar e também em relação aos efeitos que ela exerceria sobre o mercado. Uma vez que os agentes se adaptaram à nova realidade, as demais intervenções não causaram surpresa e consequentemente não impactaram os ativos.

\section{Considerações Finais}

O Banco Central dos Estados Unidos (FED) utilizou a compra de ativos financeiros como alternativa à política monetária tradicional (aumento/redução dos juros) na tentativa de aumentar a liquidez da economia e, por meio do aumento da oferta de moeda, estimular o crescimento econômico e acabar com o quadro recessivo no qual a economia americana se encontrava. Dessa maneira, a compra de ativos financeiros públicos e privado alterou os juros e a maturidade desses títulos. Por sua vez, os demais agentes na tentativa de manter a sua rentabilidade, realocam as suas carteiras através da adição de ativos que possuem maior risco e maior maturidade.

A hipótese defendida neste estudo foi que o QE resultou em redirecionamento dos investidores americanos, que passaram a aplicar parte de seus recursos em ativos oferecidos pelo Brasil. A baixa expectativa de crescimento da economia americana e o medo de inflação, provocado pela política monetária expansionista, estimularam os investidores a realocarem seus portfólios. Os ativos com maior risco/retorno oferecidos pelo Brasil se tornaram atrativos.

Os resultados encontrados corroboraram parcialmente a hipótese levan- 
Tabela 7: Teste BDS

\begin{tabular}{|c|c|c|c|c|c|c|}
\hline & \multicolumn{3}{|c|}{ IBOV } & \multicolumn{3}{|c|}{ IFNX } \\
\hline Período & BDS & z-Statistic & $\mathrm{p}$-valor & BDS & z-Statistic & p-valor \\
\hline 2 & 0,01 & 7,75 & 0,00 & 0,02 & 9,30 & 0,00 \\
\hline 3 & 0,03 & 10,66 & 0,00 & 0,04 & 11,92 & 0,00 \\
\hline 4 & 0,04 & 12,30 & 0,00 & 0,05 & 13,80 & 0,00 \\
\hline 5 & 0,05 & 13,69 & 0,00 & 0,06 & 15,40 & 0,00 \\
\hline 6 & 0,05 & 15,33 & 0,00 & 0,06 & 16,90 & 0,00 \\
\hline & \multicolumn{3}{|c|}{ ICON } & \multicolumn{3}{|c|}{ IGC } \\
\hline Período & BDS & z-Statistic & $\mathrm{p}$-valor & BDS & z-Statistic & p-valor \\
\hline 2 & 0,02 & 8,81 & 0,00 & 0,02 & 9,47 & 0,00 \\
\hline 3 & 0,04 & 12,16 & 0,00 & 0,04 & 12,36 & 0,00 \\
\hline 4 & 0,05 & 14,14 & 0,00 & 0,06 & 14,72 & 0,00 \\
\hline 5 & 0,06 & 15,82 & 0,00 & 0,07 & 16,64 & 0,00 \\
\hline 6 & 0,06 & 17,44 & 0,00 & 0,07 & 18,77 & 0,00 \\
\hline & \multicolumn{3}{|c|}{ IDIV } & \multicolumn{3}{|c|}{ IGCT } \\
\hline Período & BDS & z-Statistic & p-valor & BDS & z-Statistic & p-valor \\
\hline 2 & 0,02 & 8,44 & 0,00 & 0,02 & 8,92 & 0,00 \\
\hline 3 & 0,04 & 12,33 & 0,00 & 0,04 & 11,79 & 0,00 \\
\hline 4 & 0,05 & 14,63 & 0,00 & 0,05 & 14,09 & 0,00 \\
\hline 5 & 0,06 & 16,73 & 0,00 & 0,06 & 15,98 & 0,00 \\
\hline 6 & 0,07 & 18,94 & 0,00 & 0,07 & 17,99 & 0,00 \\
\hline & \multicolumn{3}{|c|}{ IEE } & \multicolumn{3}{|c|}{ IMAT } \\
\hline Período & BDS & z-Statistic & p-valor & BDS & z-Statistic & p-valor \\
\hline 2 & 0,02 & 11,74 & 0,00 & 0,02 & 8,16 & 0,00 \\
\hline 3 & 0,04 & 14,85 & 0,00 & 0,03 & 10,59 & 0,00 \\
\hline 4 & 0,06 & 16,12 & 0,00 & 0,04 & 12,29 & 0,00 \\
\hline 5 & 0,06 & 17,39 & 0,00 & 0,05 & 13,37 & 0,00 \\
\hline 6 & 0,07 & 18,99 & 0,00 & 0,05 & 14,79 & 0,00 \\
\hline & \multicolumn{3}{|c|}{ ISE } & \multicolumn{3}{|c|}{ INDX } \\
\hline Período & BDS & z-Statistic & p-valor & BDS & z-Statistic & p-valor \\
\hline 2 & 0,02 & 10,07 & 0,00 & 0,02 & 10,11 & 0,00 \\
\hline 3 & 0,04 & 13,03 & 0,00 & 0,04 & 13,17 & 0,00 \\
\hline 4 & 0,06 & 15,38 & 0,00 & 0,06 & 15,72 & 0,00 \\
\hline 5 & 0,07 & 17,35 & 0,00 & 0,07 & 17,63 & 0,00 \\
\hline 6 & 0,07 & 19,44 & 0,00 & 0,07 & 19,65 & 0,00 \\
\hline & \multicolumn{3}{|c|}{ ITAG } & \multicolumn{3}{|c|}{ IVBX2 } \\
\hline Período & BDS & z-Statistic & p-valor & BDS & z-Statistic & p-valor \\
\hline 2 & 0,02 & 10,03 & 0,00 & 0,02 & 10,90 & 0,00 \\
\hline 3 & 0,04 & 12,75 & 0,00 & 0,04 & 13,96 & 0,00 \\
\hline 4 & 0,06 & 14,91 & 0,00 & 0,06 & 16,40 & 0,00 \\
\hline 5 & 0,06 & 16,66 & 0,00 & 0,07 & 18,33 & 0,00 \\
\hline 6 & 0,07 & 18,48 & 0,00 & 0,07 & 20,27 & 0,00 \\
\hline \multicolumn{7}{|c|}{ UTIL } \\
\hline Período & BDS & z-Statistic & p-valor & & & \\
\hline 2 & 0,02 & 11,43 & 0,00 & & & \\
\hline 3 & 0,04 & 14,48 & 0,00 & & & \\
\hline 4 & 0,06 & 15,91 & 0,00 & & & \\
\hline 5 & 0,06 & 17,56 & 0,00 & & & \\
\hline 6 & 0,07 & 19,45 & 0,00 & & & \\
\hline
\end{tabular}


Tabela 8: Teste H: resultados encontrados

\begin{tabular}{l|ccl}
\hline Ativo & Janelas & Janelas (\%) & $\begin{array}{l}\text { Quantitative Easing, janelas } \\
\text { significativas }\end{array}$ \\
\hline UTIL & 5 & $7 \%$ & $25 / 08 / 2008,18 / 03 / 2009$ e $12 / 09 / 2012$ \\
IEE & 6 & $9 \%$ & $25 / 08 / 2008$ e $12 / 09 / 2012$ \\
IBOV & 4 & $6 \%$ & $25 / 08 / 2008$ \\
ICON & 5 & $7 \%$ & $25 / 08 / 2008$ \\
IFNX & 6 & $9 \%$ & $25 / 08 / 2008$ \\
INDX & 6 & $9 \%$ & $25 / 08 / 2008$ \\
IMAT & 3 & $4 \%$ & $25 / 08 / 2008$ \\
ISE & 6 & $9 \%$ & $25 / 08 / 2008$ \\
IGC & 4 & $6 \%$ & $25 / 08 / 2008$ \\
IGCT & 3 & $4 \%$ & $25 / 08 / 2008$ \\
ITAG & 5 & $7 \%$ & $25 / 08 / 2008$ \\
IVBX2 & 3 & $4 \%$ & $25 / 08 / 2008$ \\
IDIV & 5 & $7 \%$ & $25 / 08 / 2008$ \\
\hline
\end{tabular}

tada. Os testes Runs, Taxa de Variância e Taxa de Variância Múltipla indicaram a presença de estruturas de dependência lineares nas séries de retornos analisadas. Por sua vez, o teste ARCH-LM e o teste BDS apontaram para a presença de estruturas de dependência não lineares. Ademais, o estudo de eventos indicou que o QE influenciou no retorno de alguns dos indicadores setoriais analisados. Todavia, o teste $\mathrm{H}$ mostrou que apenas a primeira fase do QE1 resultou na formação generalizada de estruturas de dependência não lineares nos diversos indicadores de mercado considerados. As únicas exceções encontradas foram no IEE, que foi influenciado pela segunda etapa do QE1, e o UTIL, que foi influenciado pela segunda etapa do QE1 e pela primeira etapa do QE3.

Duas possíveis explicações são levantadas para os resultados encontrados, a saber: 1) O anúncio do QE1 surpreendeu os investidores americanos. A incerteza sobre a forma como o FED conduziria essas intervenções e os seus efeitos levaram os investidores a realocar os seus recursos para o mercado financeiro brasileiro. Contudo, a experiência obtida com a primeira intervenção do FED fez com que os agentes não reagissem de forma tão brusca nas demais intervenções realizadas. Estes se adaptaram após o primeiro anúncio do QE, sua incerteza se reduziu e preferiram manter ativos americanos em suas carteiras em detrimento dos ativos brasileiros.

2) A primeira intervenção do FED via $Q E$ aumentou a expectativa de inflação entre os investidores, o que os estimulou a aplicarem nos ativos brasileiros. A primeira intervenção do FED não foi suficiente para estimular a economia americana e não resultou em elevação da inflação. Consequentemente, o medo de instabilidade econômica elevada se dissipou e as demais intervenções não surpreenderam os investidores.

\section{Referências Bibliográficas}

Almeida, H. J. F., Giovanini, A., Oliveira Saath, K. C. \& Biage, M. (2018), 'A política de quantitative easing adotada pelo Fed altera a volatilidade dos ativos no Brasil?', Análise Econômica 36(69). 
Bauer, M. D. \& Rudebusch, G. D. (2014), 'Monetary policy expectations at the zero lower bound', Available at SSRN 2334540 .

Bernanke, B. (2012), Monetary policy since the onset of the crisis, in 'Federal Reserve Bank of Kansas City Economic Symposium, Jackson Hole, Wyoming', Vol. 31.

Bernanke, B. S. (2010), The economic outlook and monetary policy, in 'Speech at the Federal Reserve Bank of Kansas City Economic Symposium, Jackson Hole, Wyoming', Vol. 27.

Bordo, M. D. (2014), 'Exiting from low interest rates to normality: an historical perspective', HOOVER INSTITUTION, Economics Working Papers .

Breedon, F., Chadha, J. S. \& Waters, A. (2012), 'The financial market impact of UK quantitative easing', Oxford Review of Economic Policy 28(4), 702-728.

Brooks, C., Garrett, I. \& Hinich, M. J. (1999), 'An alternative approach to investigating lead-lag relationships between stock and stock index futures markets', Applied Financial Economics 9(6), 605-613.

URL: https://doi.org/10.1080/096031099332050

Brown, S. J. \& Warner, J. B. (1980), 'Measuring security price performance', Journal of financial economics 8(3), 205-258.

Carvalho, R., Ranasinghe, D. \& Wilkes, T. (2019), 'The life and times of ECB quantitative easing, 2015-18', urlhttps://www.reuters.com/article/useurozone-ecb-qe/the-life-and-times-of-ecb-quantitative-easing-2015-18idUSKBN1OB1SM.

Chow, K. V. \& Denning, K. C. (1993), 'A simple multiple variance ratio test', Journal of Econometrics 58(3), 385-401.

Claeys, G. \& Leandro, A. (2016), The European Central Bank's quantitative easing programme: limits and risks, Technical report, Bruegel Policy Contribution.

Cruz, P. H. S. (2017), 'O Quantitative Easing como resposta do Fed a crise financeira de 2008'.

D'Amico, S. \& King, T. (2010), 'Flow and stock effects of large-scale treasury purchases', Finance and Economics Discussion Series No. (52).

Engle, R. F. (1982), 'Autoregressive conditional heteroscedasticity with estimates of the variance of United Kingdom inflation', Econometrica: Journal of the Econometric Society pp. 987-1007.

Fama, E. F. (1970), 'Efficient capital markets: A review of theory and empirical work*', The journal of Finance 25(2), 383-417.

Freire, G. (2017), The effects of the ECB's unconventional monetary policies on stock markets, $\mathrm{PhD}$ thesis.

Fujiki, H., Okina, K. \& Shiratsuka, S. (2001), 'Monetary policy under zero interest rate: viewpoints of central bank economists', Monetary and Economic Studies 19(1), 89-130. 
Gagnon, J., Raskin, M., Remache, J. \& Sack, B. (2011), 'The financial market effects of the Federal Reserve's large-scale asset purchases', International Journal of Central Banking 7(1), 3-43.

Grassberger, P. \& Procaccia, I. (1983), 'Characterization of strange attractors', Physical review letters 50(5), 346.

Hamilton, J. D. \& Wu, J. C. (2012), 'The effectiveness of alternative monetary policy tools in a zero lower bound environment', Journal of Money, Credit and Banking 44(s1), 3-46.

Hara, K. (2014), 'Impacto das políticas monetária não convencional dos EUA nas variáveis financeiras do Brasil pós crise de 2008'.

Hausman, J. \& Wongswan, J. (2011), 'Global asset prices and FOMC announcements', Journal of International Money and Finance 30(3), 547-571.

Homburg, S. (2017), 'A study in monetary macroeconomics'.

Joyce, M., Tong, M. \& Woods, R. (2011), 'The united kingdom's quantitative easing policy: design, operation and impact', Bank of England Quarterly Bulletin.

Junior, K. M. \& Galvão, A. C. (2019), 'O impacto do fim da política monetária americana não convencional sobre a economia brasileira', Perspectiva Econômica 14(2), 92-107.

Krishnamurthy, A. \& Vissing-Jorgensen, A. (2011), The effects of quantitative easing on interest rates: channels and implications for policy, Technical report, National Bureau of Economic Research.

Lavigne, R., Sarker, S. \& Vasishtha, G. (2014), 'Spillover effects of quantitative easing on emerging-market economies', Bank of Canada Review 2014(Autumn), 23-33.

Lellis Junior, L. C. (2015), 'O impacto da quantitative easing americano no preço dos ativos brasileiros', Dissertação de Mestrado - Fundação Getúlio Vargas, Escola de Pós-Graduação emEconomia. Rio de Janeiro, RJ. .

Lim, K.-P., Brooks, R. D. \& Hinich, M. (2006), 'Testing the assertion that emerging asian stock markets are becoming more efficient', Available at SSRN 906515 .

Lim, K.-P., Hinich, M. J. \& Liew, V. K.-S. (2003), 'Episodic non-linearity and non-stationarity in ASEAN exchange rates returns series', Labuan Bulletin of International Business and Finance 1(2), 79-93.

Lo, A. W. \& MacKinlay, A. C. (1988), 'Stock market prices do not follow random walks: evidence from a simple specification test', Review of financial studies 1(1), 41-66.

Meaning, J. \& Zhu, F. (2011), 'The impact of recent central bank asset purchase programmes', BIS Quarterly Review, December.

Meier, A. (2009), Panacea, curse, or nonevent? Unconventional monetary policy in the United Kingdom, International Monetary Fund. 
Meneses, J. C. F. (2016), Será que a política de quantitative easing representa uma oportunidade para o investidor?, PhD thesis.

Neely, C. (2019), 'The asset holdings of the Bank of Japan', url: https://research.stlouisfed.org/publications/ economic-synopses/2019/07/15/the-asset-holdings-of-the-bank-of-japan.

Neely, C. J. (2010), The large scale asset purchases had large international effects, Federal Reserve Bank of St. Louis, Research Division.

Neely, C. J., Weller, P. A. \& Ulrich, J. M. (2009), 'The adaptive markets hypothesis: evidence from the foreign exchange market', Journal of Financial and Quantitative Analysis 44(02), 467-488.

Pattipeilohy, C., Van Den End, J. W., Tabbae, M., Frost, J. \& De Haan, J. (2013), 'Unconventional monetary policy of the ECB during the financial crisis: an assessment and new evidence'.

Pretorius, R. (2018), The Bank of Japan's intervention in exchange-traded funds as an effective monetary policy tool, $\mathrm{PhD}$ thesis, University of Cape Town.

Saadi, S., Gandhi, D. \& Elmawazini, K. (2006), 'On the validity of conventional statistical tests given evidence of non-synchronous trading and nonlinear dynamics in returns generating process', Applied Economics Letters 13(5), 301-305. 
